\title{
Solubilization and adsorption behaviors of 2,4,6-trichlorophenol in the presence of surfactants
}

\author{
Qinghui Zeng ${ }^{\mathrm{a}, \mathrm{b}}$, Sha Peng ${ }^{\mathrm{a}}$, Min Liu ${ }^{\mathrm{a}}$, Zijian Song ${ }^{\mathrm{a}}$, Xiankai Wang ${ }^{\mathrm{a}}$, Xu Zhang ${ }^{\mathrm{a}}$, Song Hong ${ }^{\mathrm{a}, *}$ \\ ${ }^{a}$ School of Resource and Environmental Science, Wuhan University, Wuhan 430079, People's Republic of China \\ ${ }^{\mathrm{b}}$ Research Center for Eco-Environmental Sciences, Chinese Academy of Sciences, Beijing 100085, People's Republic of China
}

\section{H I G H L I G H T S}

- The solubility of 2,4,6-trichlorophenol was enhanced 72 times by sodium deoxycholateat pH 7.5.

- NaDC demonstrated the best solubilization potential, followed by NaC, SDS and $\beta$-CD.

- The adsorption of 2,4,6-trichlorophenol was almost zero when $\mathrm{NaC}$ concentration was above $\mathrm{CMC}_{2}$.

\section{A R T I C L E I N F O}

\section{Article history:}

Received 12 April 2013

Received in revised form 15 June 2013

Accepted 17 June 2013

Available online 28 June 2013

\section{Keywords:}

Solubilization

Adsorption

Surfactant

Sodium deoxycholate

2,4,6-Trichlorophenol

Soil remediation

\begin{abstract}
A B S T R A C T
The solubilization of 2,4,6-trichlorophenol (2,4,6-TCP) was studied in the presence of four different surfactants, namely sodium deoxycholate $(\mathrm{NaDC})$, sodium cholate $(\mathrm{NaC})$, sodium lauryl sulfate $(\mathrm{SDS})$ and $\beta$ cyclodextrin ( $\beta-\mathrm{CD}$ ). The solubility of 2,4,6-TCP was enhanced a maximum of 72 times especially by NaDC at $\mathrm{pH}$ 7.5. In addition, other than great solubilization capacities, $\mathrm{NaDC}$ and $\mathrm{NaC}$ have the advantages of high biodegradability and biocompatibility as biosurfactants. The adsorption behaviors of 2,4,6-TCP on the surface of soil in the presence of these solubilizers were examined. The results showed that the adsorption isotherms for all studied surfactants matched the Henry adsorption isotherm well. The adsorption mechanisms were explored and the adsorption behaviors of 2,4,6-TCP were affected by different micelle forms of the surfactants based on their critical micelle concentration (CMC). The adsorption process was demonstrated by a redistribution procedure between surfactants in solution and surfactants adsorbed onto the soil surface. In particular, the adsorption of 2,4,6-TCP was almost zero when NaC concentration was above $\mathrm{CMC}_{2}$. The results of our study have important implications for soil remediation and non-point source pollution control.
\end{abstract}

(c) 2013 Elsevier B.V. All rights reserved.

\section{Introduction}

The contamination of soils and groundwater by toxic and/or hazardous organic compounds has become a widespread environmental problem, therefore the removal of hydrophobic organic compounds (HOCs) from them has received serious consideration $[1,2]$. In response to a growing need to address environmental contamination, many remediation technologies have been developed to treat soil $[3,4]$. Surfactant-enhanced soil remediation (SESR) has long been known as the most effective and promising technique for the removal of hydrophobic pollutants from soil and water [5-8]. The selection of suitable surfactants to be employed in soil washing is a very important task for the successful application of SESR technology [9-11].

There have been many published studies in the literature on the solubilization behaviors of surfactants [12-14]. It has been well

\footnotetext{
* Corresponding author. Tel.: +86 27 87322320; fax: +86 2787322109 .

E-mail address: songhongpku@126.com (S. Hong).
}

known that surfactants can remediate soils by solubilizing HOCs and then enhancing the desorption of HOCs from soils $[15,16]$. Even so, some research has indicated that the surfactants would also adsorb onto the soil matrix and thereby lead to HOCs partitioning into the immobilised adsorbed surfactants [17-20]. This would result in a rebound in HOCs adsorption capacity onto the soil [2]. Solubilization of HOCs into surfactant aggregates adsorbed on solid surfaces is sometimes referred to as "adsolubilization" [21]. Obviously, it is very important to find a suitable surfactant which has minimal adsorption onto the soil as well as an effective ability for solubilization.

To make the technology feasible and economical, the surfactant must be safe and effective. While traditional surfactants have the problems of low biodegradability and generation of toxic degradation products, they will also have certain detrimental effects on humans and animals [22]. Recently, biosurfactants have gained more attention compared to synthetic surfactants due to the environmentally compatible nature of those compounds [17]. Biosurfactants can be as effective as the highly used synthetic surfactants, 
and at the same time have some distinct advantages over synthetic surfactants, including high specificity, biodegradability and biocompatibility [22].

Initially in this research, sodium deoxycholate (NaDC) and sodium cholate $(\mathrm{NaC})$ were chosen as representatives of biosurfactants. The solubilization capacities of $\mathrm{NaDC}$ and $\mathrm{NaC}$ were compared with $\beta$-cyclodextrin $(\beta-C D)$ and Sodium Dodecyl Sulfate (SDS), two frequently used synthetic surfactants. Then, the adsorption behaviors of 2,4,6-trichlorophenol (2,4,6-TCP) in the presence of $\mathrm{NaDC}, \mathrm{NaC}$ and SDS were studied. Third, to the best of our knowledge, little research had taken the CMC of surfactants into consideration during the adsorption experiments. Therefore, the effects of different micellar forms on adsorption behaviors were also studied, and the possible adsorption mechanisms were discussed. The objectives of this study were to find safe and efficient solubilizers to remove 2,4,6-TCP, a widespread environmental contaminant, from soils [23]. Meanwhile, the effects of different micellar forms on the adsorption behaviors were explored and the optimum concentration for each surfactant was discussed.

\section{Materials and methods}

\subsection{Materials}

2,4,6-TCP (98\%), NaC (98\%), NaDC (98\%), $\beta$-CD (98\%) and SDS $(\geqslant 99 \%)$ were purchased from the Aladdin chemical company. The chemical properties of the selected surfactants are shown in Table 1 (including Refs. [24-26]). The soil was stored in brown reagent bottles after sieving (200-mesh). Some characteristics of the soil are summarized in Table 2.

\subsection{Methods}

Solubilization studies were conducted by adding an excess amount of 2,4,6-TCP in $10 \mathrm{~mL}$ solution, with the initial concentration of surfactants spanned over a wide range of values below and above its CMC (0-100 mmol/L for NaDC, $\mathrm{NaC}$ and SDS, 0-10 mmol/ $\mathrm{L}$ for $\beta-C D$ due to the restriction of its own solubility). After 1-h heating in a water bath (at a temperature of $80^{\circ} \mathrm{C}$ ), the $2,4,6$-TCP was dissolved to saturation. The bottles were put in a rotary shaker for $12 \mathrm{~h}$ at room temperature $\left(15^{\circ} \mathrm{C}\right)$ so that the excess dissolved
Table 2

Properties of soil sample.

\begin{tabular}{ll}
\hline Parameter & Soil sample \\
\hline Specific surface area $\left(\mathrm{m}^{2} / \mathrm{g}\right)$ & 0.0031 \\
Particle size $(\mu \mathrm{m})$ & 71.445 \\
Iso-electric point & Around pH 10.5 \\
X-ray fluorescence analysis (top 10) & $\mathrm{O}(48.1 \%), \mathrm{Si}(25.2 \%), \mathrm{Al}(8.87 \%)$, \\
& $\mathrm{Fe}(8.80 \%), \mathrm{S}(3.93 \%), \mathrm{K}(2.93 \%), \mathrm{Mg}$ \\
& $(0.639 \%), \mathrm{Ti}(0.521 \%), \mathrm{Ca}$ \\
& $(0.326 \%), \mathrm{Na}(0.209 \%)$ \\
\hline
\end{tabular}

2,4,6-TCP precipitated. Afterwards, samples were centrifuged at $8000 \mathrm{rpm}$ for $10 \mathrm{~min}$, and the supernatants were diluted 10 times to the range of the marking line. The detection was analyzed by high performance liquid chromatography (HPLC) and UV spectrophotometry as appropriate to the surfactant added. The HPLC analyses were performed isocratically using a mobile phase of $70 \%$ methanol, $1 \%$ glacial acetic acid and $29 \%$ water at a flow rate of $1.5 \mathrm{~mL} / \mathrm{min}$. The UV detection wavelength was $280 \mathrm{~nm}$ and the sample injection volume was $20 \mu \mathrm{L}$. Different pH effects were also explored in this solubilization research ( $\mathrm{pHs}$ were adjusted by the addition of small amounts of dilute $\mathrm{HCl}$ and $\mathrm{NaOH}$ ).

Adsorption studies were conducted by placing a constant ratio of soil $(1 \mathrm{~g} / \mathrm{L})$ in $50 \mathrm{~mL}$ mixed solution at room temperature, with the concentration of 2,4,6-TCP varied from 0 to $200 \mathrm{mg} / \mathrm{L}$. The concentration of surfactants varied according to their CMCs. The bottles were put in a shaker for $2.5 \mathrm{~h}$ to reach the adsorption equilibrium (preliminary experiments revealed that $2.5 \mathrm{~h}$ is long enough to reach equilibrium). The detection method was the same as above. Parallel tests were conducted in all cases with appropriate blanks.

\section{Results and discussion}

3.1. Solubilization of 2,4,6-TCP in the presence of $\mathrm{NaDC}, \mathrm{NaC}$, SDS and $\beta-C D$

3.1.1. Apparent solubility of 2,4,6-TCP in the presence of $\mathrm{NaDC}, \mathrm{NaC}$, SDS and $\beta-C D$

The solubilization potential of $\mathrm{NaDC}, \mathrm{NaC}, \mathrm{SDS}$ and $\beta-\mathrm{CD}$ was evaluated with 2,4,6-TCP at various pHs. Surfactants are

Table 1

Properties of surfactants used in this study.

\begin{tabular}{|c|c|c|c|c|c|c|}
\hline Surfactant & Molecular formula & MW & Molecular structure & $\mathrm{CMC}(\mathrm{mM})$ & & Refs. \\
\hline $\mathrm{NaDC}$ & $\mathrm{C}_{24} \mathrm{H}_{39} \mathrm{NaO}_{4}$ & 414.56 & & $2.3\left(\mathrm{CMC}_{1}\right)$ & $6.1\left(\mathrm{CMC}_{2}\right)$ & {$[24]$} \\
\hline $\mathrm{NaC}$ & $\mathrm{C}_{24} \mathrm{H}_{39} \mathrm{NaO}_{5}$ & 430.56 & & $6.1\left(\mathrm{CMC}_{1}\right)$ & $12.3\left(\mathrm{CMC}_{2}\right)$ & {$[24]$} \\
\hline$\beta-C D$ & $\mathrm{C}_{42} \mathrm{H}_{70} \mathrm{O}_{35}$ & 1134.98 & & $104-116$ & & {$[25]$} \\
\hline SDS & $\mathrm{NaC}_{12} \mathrm{H}_{25} \mathrm{SO}_{4}$ & 288.38 & & 8.2 & & {$[26]$} \\
\hline
\end{tabular}


amphiphilic compounds containing both hydrophilic head groups and hydrophobic tail groups [27]. The enhanced solubilization effects of surfactants for HOCs is usually used as an index in evaluating the capabilities of surfactants in removing HOCs from contaminated soils [1].

Fig. 1 compared the solubilization capacities of four studied surfactants. Symbols are experimental data with error bars expressing the standard deviations. According to Fig. 1, for all studied surfactants and pHs, the solubility of 2,4,6-TCP increased with increasing surfactant concentration in a linear pattern. Relevant solubilization of HOCs occurs when the CMC of surfactant is reached and the solubilization becomes proportional to the surfactant concentration above the CMC $[9,28,29]$. This phenomenon is called a "partitionlike" interaction between the HOCs and the non-polar group of the dilute surfactant $[7,30]$. The result that the equilibrium of 2,4,6-TCP apparent solubility was increased in proportion to the surfactant concentrations was consistent with the research of Huang and Lee [27]. This article explained that surfactant monomers had the ability, related to the hydrophobicity of HOCs, to enhance aqueous concentrations. According to the research of Hofmann, the micelle of bile salts provides an amphipathic region in which water-insoluble substances can dissolve. The hydrophobic side of bile salts is believed to be adsorbed to HOCs, and the hydrophilic side of the bile acid faces outward, thus increases the solubility of HOCs [31]. However, there were some distinctions in the changing trend. For NaDC, the solubilization capacity was first increased then decreased with the increase in $\mathrm{pH}$ value, and the maximum solubility of 2,4,6-TCP was $42775.93 \mathrm{mg} / \mathrm{L}$ at the optimal pH 7.5. According to the research of Sobotka, the gelation of deoxycholic acid was observed between $\mathrm{pH} 6.4$ and 7.8. The occurrence of gel at $\mathrm{pH} 7$ and 7.5 may increase the solubility of 2,4,6TCP, therefore the solubilization capacity of NaDC decreased at $\mathrm{pH}$ 8. However, no gelation is observed in the case of cholic acid
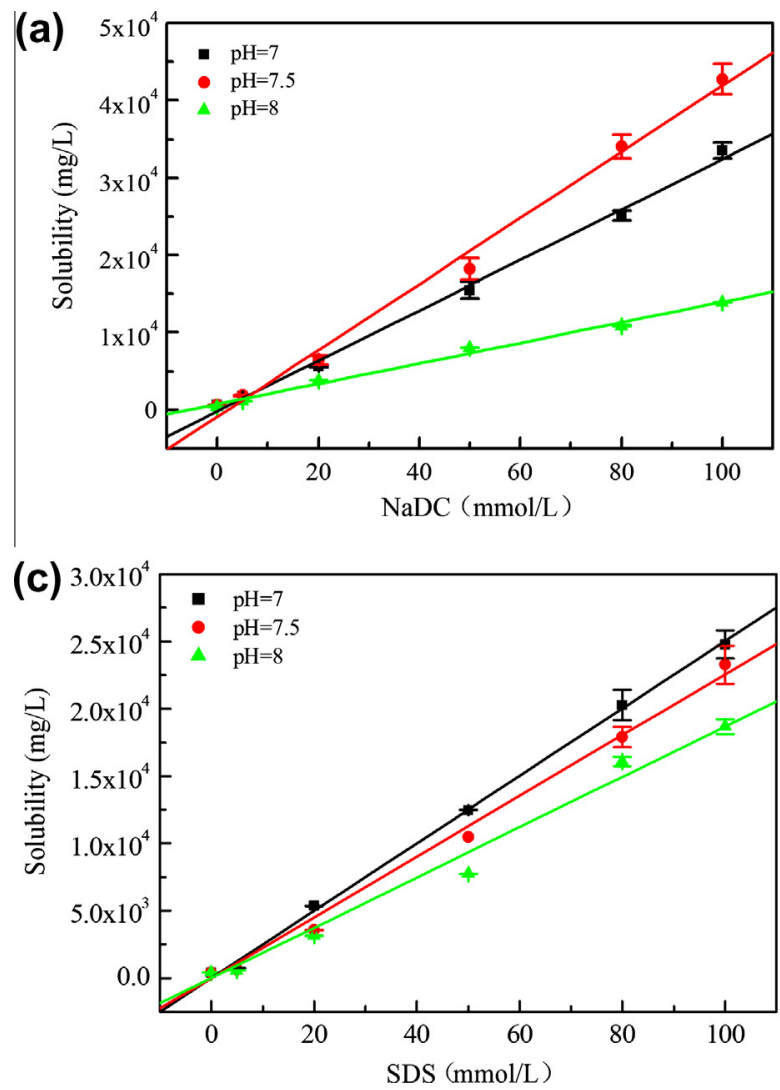

[32]. For NaC, The solubility of 2,4,6-TCP was generally showing a upward trend with the increase in $\mathrm{pH}$ value, and the maximum solubility of $2,4,6$-TCP was $33585.36 \mathrm{mg} / \mathrm{L}$ at the optimal $\mathrm{pH} 8.0$. The solubility of 2,4,6-TCP in the presence of NaDC and NaC depends on the $\mathrm{pH}$. At $\mathrm{pH} \mathrm{7,} \mathrm{solubility} \mathrm{of} \mathrm{2,4,6-TCP} \mathrm{in} \mathrm{the} \mathrm{presence}$ of $\mathrm{NaC}<$ solubility in the presence of $\mathrm{NaDC}$, while at $\mathrm{pH} 8$, solubility of $2,4,6-\mathrm{TCP}$ in the presence of $\mathrm{NaC}>$ solubility in the presence of $\mathrm{NaDC}$.

As to SDS, the solubility showed a descending trend with the increase in $\mathrm{pH}$ value. One possible explanation was that as the $\mathrm{pH}$ went up, more electrolyte was added to the solution, and these hydroxyl ions would reduce the electrical repulsion in the micelle as well as the thickness of the ionic layer surrounding the head-group [27]. This would reduce the size of the micelles, thus leading to a reduction of included 2,4,6-TCP, so that the solubility decreased.

On the other hand, the solubilization capacity of SDS was considerable, while the solubilization capacity of $\beta-C D$ was not obvious. According to the results of a previous study [33], the molar efficiency of the surfactants was lower than that of the cyclodextrins. It was explained that surfactant-enhanced solubilization was based on the formation of micelles, while cyclodextrin-enhanced solubilization was based on one-to-one inclusion complexes. However, this result was contrary to ours, which showed that the efficiency of the surfactants was higher than that of $\beta$ CD. This was probably because the size of 2,4,6-TCP was bigger than the cavity of $\beta-\mathrm{CD}$, therefore, it is hard for $2,4,6$-TCP to enter the cavity. As a result, $\beta-C D$ cannot significantly increase the solubility of 2,4,6-TCP.

\subsubsection{Molar solubilization ratio (MSR) of NaDC, NaC, SDS and $\beta-C D$}

MSR is an index often used to evaluate the effectiveness of a surfactant in solubilizing a given solute, and it was obtained in this study by the method of Edwards et al. [34].
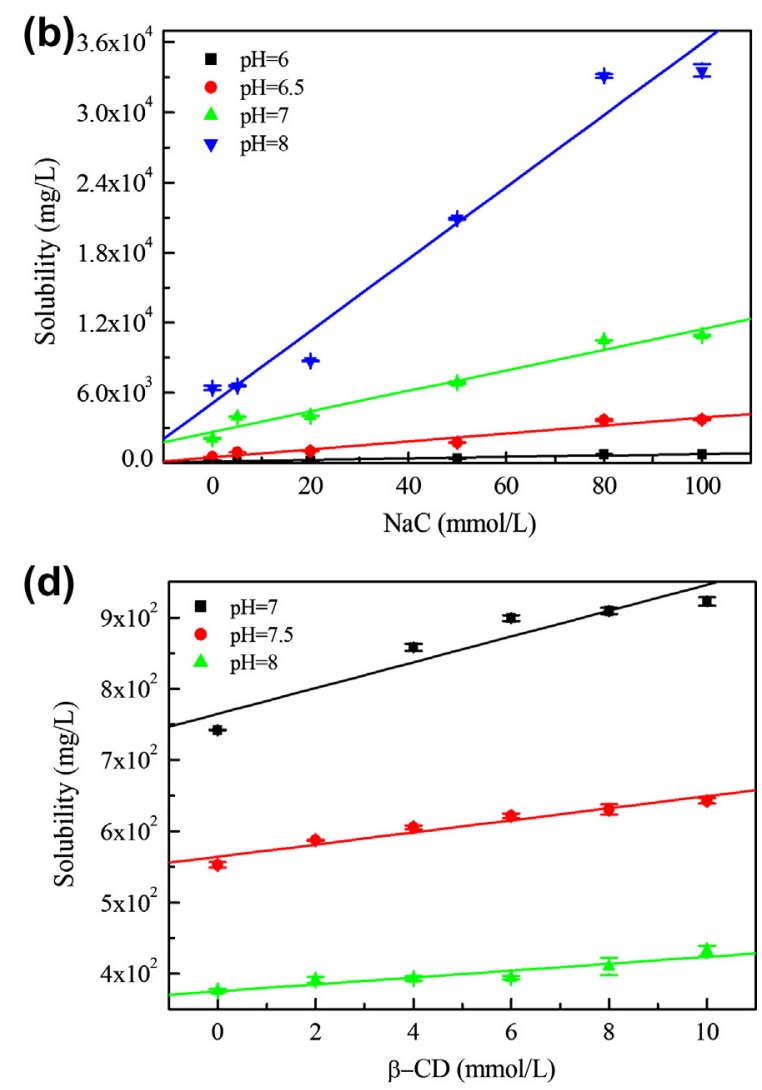

Fig. 1. The solubilization of $2,4,6-\mathrm{TCP}$ in the presence of surfactants at various pHs. (a) NaDC, (b) NaC, (c) SDS, (d) $\beta-C D$. 
$\operatorname{MSR}=\left(S_{\text {mic }}-S_{\text {cmc }}\right) /\left(C_{\text {surf }}-\mathrm{CMC}\right)$

where $S_{\mathrm{cmc}}$ is the apparent solubility of 2,4,6-TCP in moles per liter at the CMC; $S_{\text {mic }}$ is the total apparent solubility of 2,4,6-TCP in moles per liter in micellar solutions at a particular surfactant concentration greater than the CMC; and $C_{\text {surf }}$ is the surfactant concentration at which $S_{\text {mic }}$ is evaluated. The MSR can be obtained from the slope of the solubility curve above the critical micelle concentration [2].

The MSR values were obtained from slopes in Fig. 1 based on Eq. (1), and the maximum solubility and MSR value of studied surfactants were summarized in Table 3 . We can conclude that the trends in MSR values were consistent with the trends in solubility changes at various pHs. The maximum MSR values for the studied surfactants were $428 \pm 20$ for $\mathrm{NaDC}$ at $\mathrm{pH} 7.5,308 \pm 3.2$ for $\mathrm{NaC}$ at $\mathrm{pH}$ 8.0, $249 \pm 8.5$ for SDS at $\mathrm{pH} 7.0$ and $18.1 \pm 0.13$ for $\beta-\mathrm{CD}$ at $\mathrm{pH} 7.0$. From the MSR point of view, NaDC appeared to be the most efficient surfactant to increase the solubility of 2,4,6-TCP, followed by $\mathrm{NaC}$ and SDS, while the solubilization effect of $\beta-\mathrm{CD}$ was not obvious.

\subsubsection{Micellar partition coefficient $\left(K_{\text {mic }}\right)$ of 2,4,6-TCP in the presence} of $\mathrm{NaDC}, \mathrm{NaC}, \mathrm{SDS}$ and $\beta-C D$

Solubilization of HOCs in surfactant micelles can be seen as an allocation process, and we can use $K_{\text {mic }}$ to estimate the concentration of 2,4,6-TCP distributed into the micellar phase. It can be calculated with Eq. (2) by the method of Kile and Chiou [7]:

$S_{\mathrm{w}}^{*} / S_{w}=1+C_{\mathrm{mn}} K_{\mathrm{mn}}+C_{\mathrm{mc}} K_{\mathrm{mc}}$

where $S_{\mathrm{w}}^{*}$ is the apparent solute solubility at the total stoichiometric surfactant concentration of $C, S_{\mathrm{w}}$ is the intrinsic solubility in "pure water", $C_{\mathrm{mn}}$ is the concentration of the surfactant as monomers, and $C_{\mathrm{mc}}$ is the concentration of the surfactant in micellar form. The $K_{\mathrm{mn}}$ term is the partition constant of the solute between monomers and water and the $K_{\mathrm{mc}}$ term is the corresponding partition constant of the solute between micelles and water.

For a certain solute-surfactant system, when the surfactant concentration is above CMC, $C_{\mathrm{mn}}=\mathrm{CMC}$ and $C_{\mathrm{mc}}=C_{\text {surf }}-\mathrm{CMC}$, Eq. (2) can be simplified as:

$S_{\mathrm{w}}^{*} / S_{\mathrm{w}}=C_{\mathrm{surf}} K_{\mathrm{mc}}+C_{1}$

where $C_{\text {surf }}$ is the surfactant concentration at which $S_{\text {mic }}$ is evaluated, and $C_{1}=1+\left(K_{\mathrm{mn}}-K_{\mathrm{mc}}\right) \mathrm{CMC}$, is a constant. $K_{\mathrm{mc}}$ can be

Table 3

Maximum solubility and MSR values of 2,4,6-TCP in the presence of NaDC, NaC, SDS and $\beta-C D$.

\begin{tabular}{lllll}
\hline Component & $\mathrm{pH}$ & $S_{\max }{ }^{\mathrm{a}}(\mathrm{mg} / \mathrm{L})$ & MSR $^{\mathrm{b}}$ & $r^{2}$ of MSR \\
\hline $\mathrm{NaDC}$ & 7.0 & $3.35 \times 10^{4}$ & $326 \pm 11$ & 0.996 \\
& 7.5 & $4.28 \times 10^{4}$ & $428 \pm 20$ & 0.994 \\
& 8.0 & $1.39 \times 10^{4}$ & $132 \pm 0.41$ & 0.992 \\
$\mathrm{NaC}$ & 6.0 & $7.41 \times 10^{2}$ & $6.62 \pm 0.10$ & 0.922 \\
& 6.5 & $3.71 \times 10^{3}$ & $33.7 \pm 0.64$ & 0.951 \\
& 7.0 & $1.09 \times 10^{4}$ & $88.1 \pm 0.34$ & 0.968 \\
$\mathrm{SDS}$ & 8.0 & $3.36 \times 10^{4}$ & $308 \pm 3.2$ & 0.970 \\
& 7.0 & $2.48 \times 10^{4}$ & $249 \pm 8.5$ & 0.998 \\
$\beta$ & 7.5 & $2.33 \times 10^{4}$ & $232 \pm 4.4$ & 0.995 \\
& 8.0 & $1.87 \times 10^{4}$ & $192 \pm 1.6$ & 0.987 \\
& 7.0 & $9.23 \times 10^{2}$ & $18.1 \pm 0.13$ & 0.901 \\
& 7.5 & $6.43 \times 10^{2}$ & $8.50 \pm 0.27$ & 0.941 \\
& 8.0 & $4.32 \times 10^{2}$ & $4.83 \pm 0.68$ & 0.878
\end{tabular}

${ }^{a} S_{\max }$ - maximum solubility (in the presence of maximum concentration of surfactants. $0-100 \mathrm{mmol} / \mathrm{L}$ for $\mathrm{NaDC}, \mathrm{NaC}$ and SDS. $0-10 \mathrm{mmol} / \mathrm{L}$ for $\beta-\mathrm{CD}$ due to the restriction of its own solubility).

b MSR - molar solubilization ratio. obtained from the slope of the solubilization multiples $\left(S_{\mathrm{w}}^{*} / S_{\mathrm{w}}\right)$ curve above the CMC.

As to the calculation of $\mathrm{NaDC}$ and $\mathrm{NaC}$, according to the research of Matsuoka and Moroi [24], there are three stages of micellization of sodium bile salts. As the concentration increases: monomer, primary aggregates and secondary aggregates of almost constant properties occur. Correspondingly, the first $\mathrm{CMC}\left(\mathrm{CMC}_{1}\right)$ was defined as the critical micelle concentration at which primary aggregates begin to form, and the second $\mathrm{CMC}\left(\mathrm{CMC}_{2}\right)$ was defined as the critical micelle concentration at which secondary aggregates begin to form [35-37]. Therefore, Eq. (2) could be modified into:

$S_{\mathrm{w}}^{*} / S_{\mathrm{w}}=1+C_{\mathrm{mn}} K_{\mathrm{mn}}+C_{\mathrm{mc} 1} K_{\mathrm{mc} 1}+C_{\mathrm{mc} 2} K_{\mathrm{mc} 2}$

where $S_{\mathrm{w}}^{*}$ is the apparent solute solubility at the total stoichiometric surfactant concentration of $C, S_{\mathrm{w}}$ is the intrinsic solubility in "pure water", $C_{\mathrm{mn}}$ is the monomer concentration of surfactant, $C_{\mathrm{mc} 1}$ is the primary aggregate concentration of surfactant, $C_{\mathrm{mc} 2}$ is the secondary aggregate concentration of surfactant, $K_{\mathrm{mn}}$ is the partition constant of the solute between monomers and water, $K_{\mathrm{mc} 1}$ is the partition constant of the solute between primary aggregates and water, $K_{\mathrm{mc}}$ is the partition constant of the solute between secondary aggregates and water.

When the surfactant concentration is above $\mathrm{CMC}_{2}, C_{\mathrm{mn}}=\mathrm{CMC}_{1}$, $C_{\mathrm{mc} 1}=\mathrm{CMC}_{2}-\mathrm{CMC}_{1}, C_{\mathrm{mc} 2}=C_{\text {surf }}-\mathrm{CMC}_{2}$. Eq. (4) can be simplified as:

$S_{\mathrm{w}}^{*} / S_{\mathrm{w}}=C_{\mathrm{surf}} K_{\mathrm{mc} 2}+C_{2}$

where $C_{2}=1+\mathrm{CMC}_{1}\left(K_{\mathrm{mn}}-K_{\mathrm{mc} 1}\right)+\mathrm{CMC}_{2}\left(K_{\mathrm{mc} 1}-K_{\mathrm{mc} 2}\right)$, is a constant. In this way, the $K_{\mathrm{mc} 2}$ can be obtained from the slope of the solubilization multiples $\left(S_{\mathrm{w}}^{*} / S_{\mathrm{w}}\right)$ curve above the critical micelle concentration.

Fig. 2 shows the $S_{\mathrm{w}}^{*} / S_{\mathrm{w}}$ of $2,4,6-\mathrm{TCP}$ at various $\mathrm{pHs}$ in the presence of surfactants. The values of $K_{\text {mic }}$ (For SDS and $\beta-C D, K_{\text {mic }}=-$ $K_{\mathrm{mc}}$; For $\mathrm{NaDC}$ and $\mathrm{NaC}, K_{\mathrm{mic}}=K_{\mathrm{mc} 2}$ ) were calculated by Eqs. (25 ) and were obtained from slopes in Fig. 2. Obviously, the changing trends of $S_{\mathrm{w}}^{*} / S_{\mathrm{w}}$ of 2,4,6-TCP were consistent with the trends of solubility of 2,4,6-TCP (Fig. 1). First, the $S_{\mathrm{w}}^{*} / S_{\mathrm{w}}$ of 2,4,6-TCP increased linearly with increasing surfactant concentration for all pHs. Secondly, the $S_{\mathrm{w}}^{*} / S_{\mathrm{w}}$ of $2,4,6-\mathrm{TCP}$ was affected by the $\mathrm{pH}$ of the solution.

The solubilization multiples and $K_{\text {mic }}$ of four surfactants are summarized in Table 4. For NaDC, the optimum pH was 7.5, and the maximum $S_{\mathrm{w}}^{*} / S_{\mathrm{w}}$ was 71.63 in the presence of $100 \mathrm{mmol} / \mathrm{L}$ $\mathrm{NaDC}$. For $\mathrm{NaC}$, the optimum $\mathrm{pH}$ was 6.5 , and the maximum $S_{\mathrm{w}}^{*} / S_{\mathrm{w}}$ was 7.42 in the presence of $100 \mathrm{mmol} / \mathrm{L} \mathrm{NaC}$. For SDS, the optimum pH was 7.0, and the maximum $S_{\mathrm{w}}^{*} / S_{\mathrm{w}}$ was 59.94 in presence of $100 \mathrm{mmol} / \mathrm{L}$ SDS. For $\beta-\mathrm{CD}$, the optimum $\mathrm{pH}$ was 7.0, and the maximum $S_{\mathrm{w}}^{*} / S_{\mathrm{w}}$ was 1.24 in presence of $10 \mathrm{mmol} / \mathrm{L} \beta-\mathrm{CD}$. The maximum $K_{\text {mic }}$ values for the studied surfactants were 0.72 in the presence of $\mathrm{NaDC}$ at $\mathrm{pH} 7.5,0.07$ in the presence of $\mathrm{NaC}$ at $\mathrm{pH} 6.5,0.60$ in the presence of SDS at $\mathrm{pH} 7.0$ and 0.02 in the presence of $\beta-\mathrm{CD}$ at $\mathrm{pH}$ 7.0. From the $K_{\text {mic }}$ point of view, NaDC was the most efficient surfactant to increase the solubility of 2,4,6-TCP, followed by SDS and $\mathrm{NaC}$, while the solubilization effect of $\beta-\mathrm{CD}$ was not obvious.

\subsubsection{The effect of 2,4,6-TCP dissociation on solubilization}

In principle, a given weak acid HA dissociates as follows in solution:

$\mathrm{HA}=\mathrm{H}^{+}+\mathrm{A}^{-}$

The acid dissociation constant $K_{\mathrm{a}}$ is given as follows:

$K_{\mathrm{a}}=\frac{\left[\mathrm{H}^{+}\right]\left[\mathrm{A}^{-}\right]}{[\mathrm{HA}]}$ 

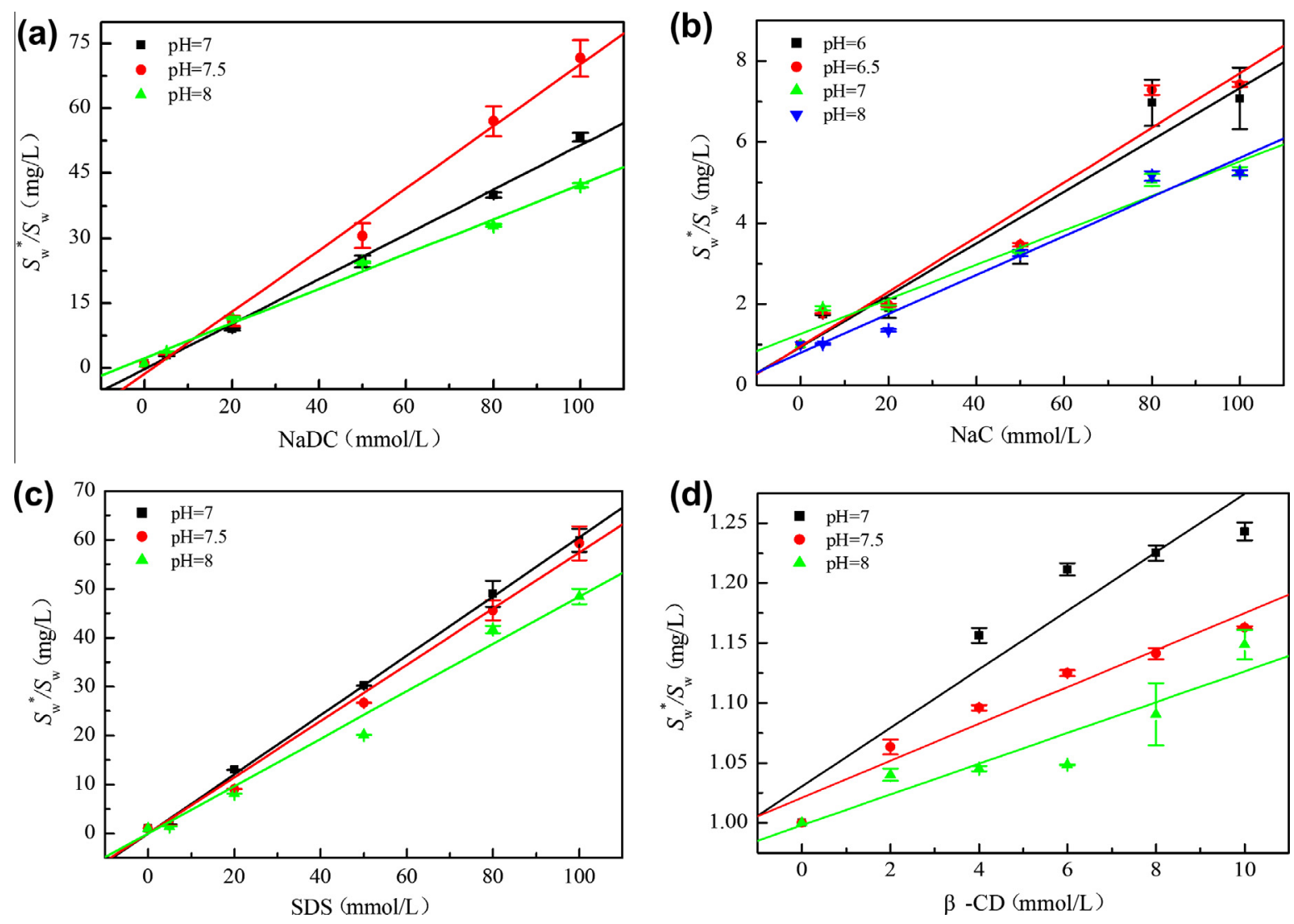

Fig. 2. The solubilization multiples $\left(S_{w}^{*} / S_{w}\right)$ of $2,4,6-\mathrm{TCP}$ in the presence of surfactants at various pHs. (a) NaDC, (b) NaC, (c) SDS, (d) $\beta$-CD.

Table 4

Solubilization multiples $\left(S_{\mathrm{w}}^{*} / S_{\mathrm{w}}\right)$ and $K_{\mathrm{mic}}$ of $\mathrm{NaDC}, \mathrm{NaC}$, SDS and $\beta-\mathrm{CD}$.

\begin{tabular}{|c|c|c|c|c|c|c|c|c|c|c|c|c|c|}
\hline Component & $\mathrm{NaDC}$ & & & $\mathrm{NaC}$ & & & & SDS & & & $\beta-C D$ & & \\
\hline $\mathrm{pH}$ & 7.0 & 7.5 & 8.0 & 6.0 & 6.5 & 7.0 & 8.0 & 7.0 & 7.5 & 8.0 & 7.0 & 7.5 & 8.0 \\
\hline$S_{\mathrm{w}}^{*} / S_{\mathrm{w}}{ }^{\mathrm{a}}$ & 53.34 & 71.63 & 42.22 & 3.71 & 7.42 & 5.27 & 5.24 & 59.94 & 59.30 & 48.40 & 1.24 & 1.16 & 1.15 \\
\hline$K_{\mathrm{mic}}^{\mathrm{b}}$ & 0.52 & 0.72 & 0.40 & 0.03 & 0.07 & 0.04 & 0.05 & 0.60 & 0.59 & 0.50 & 0.02 & 0.02 & 0.01 \\
\hline
\end{tabular}

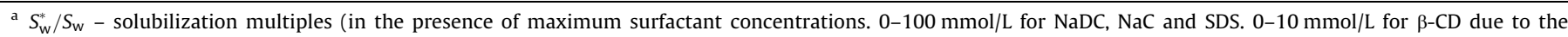
restriction of its own solubility).

${ }^{b} K_{\mathrm{mic}}-$ micelle-water partition coefficient (for SDS and $\beta-\mathrm{CD}, K_{\mathrm{mic}}=K_{\mathrm{mc}}$; for $\mathrm{NaDC}$ and NaC, $K_{\mathrm{mic}}=K_{\mathrm{mc} 2}$ ).

where $\left[\mathrm{H}^{+}\right],\left[\mathrm{A}^{-}\right]$and $[\mathrm{HA}]$ are the equilibrium concentrations of $\mathrm{H}^{+}$, $\mathrm{A}^{-}$and $\mathrm{HA}$, respectively.

Assuming the total solubility is $C_{0}$ and the dissociation concentration is $C_{1}$, the correlation of $\mathrm{p} K_{\mathrm{a}}$ and $\mathrm{pH}$ can be easily reduced as follows:

$\mathrm{p} K_{\mathrm{a}}=\mathrm{pH}+\lg \frac{[\mathrm{HA}]}{\left[\mathrm{A}^{-}\right]}=\mathrm{pH}+\lg \frac{C_{0}-C_{1}}{C_{1}}$

Dissociation rate $\delta$ can be calculated as:

$\delta=C_{1} / C_{0}=\frac{1}{10^{\mathrm{p} K_{\mathrm{a}}-\mathrm{pH}}+1}$

According to the Report on Carcinogens, Twelfth Edition (2011) [38], the dissociation constant $\left(\mathrm{p} K_{\mathrm{a}}\right)$ of $2,4,6-\mathrm{TCP}$ is 6.23 at $25^{\circ} \mathrm{C}$. Therefore, $\delta$ is a constant at any particular $\mathrm{pH}$. The calculation predicts that $\delta=37.06 \%, 65.06 \%, 85.48 \%$ and $98.33 \%$ at pHs $6,6.5,7$ and 8 , respectively.

For any straight line in Fig. 1, the apparent solubilities of random two points, $\mathrm{A}$ and $\mathrm{B}$, are $a_{0}$ and $b_{0}$, and the dissociation concentrations of these two points at this very moment are $a_{1}$ and $b_{1}$, respectively.
According to Eq. (8), $a_{1} / a_{0}=C, b_{1} / b_{0}=C$ ( $C$ is a constant $)$.

$S / S_{0}=\frac{b_{0}-b_{1}}{a_{0}-a_{1}}=\frac{b_{0}-b_{0} C}{a_{0}-a_{0} C}=\frac{b_{0}}{a_{0}}$

where $S$ is the apparent solute solubility of 2,4,6-TCP at point B, $S_{0}$ is the apparent solute solubility of $2,4,6-\mathrm{TCP}$ at point A. We can conclude that in the investigated $\mathrm{pH}$ range, the dissociation of 2,4,6TCP increased with increasing $\mathrm{pH}$, but the dissociation did not make any difference to the results of the solubilization multiple.

\subsection{Sorption behaviors of 2,4,6-TCP onto the soil in the presence of $\mathrm{NaDC}, \mathrm{NaC}$ and SDS}

\subsubsection{Sorption isotherms of 2,4,6-TCP in the presence of $\mathrm{NaDC}, \mathrm{NaC}$ and SDS}

The adsorption of 2,4,6-TCP onto the soil was evaluated in the presence of $\mathrm{NaDC}, \mathrm{NaC}$ and SDS since they all have relatively good solubilization capacities. Fig. 3 shows the 2,4,6-TCP adsorption isotherms in the presence of surfactants at various concentrations. Symbols are experimental data with error bars expressing the standard deviations. According to Fig. 3a, the adsorption isotherm in 

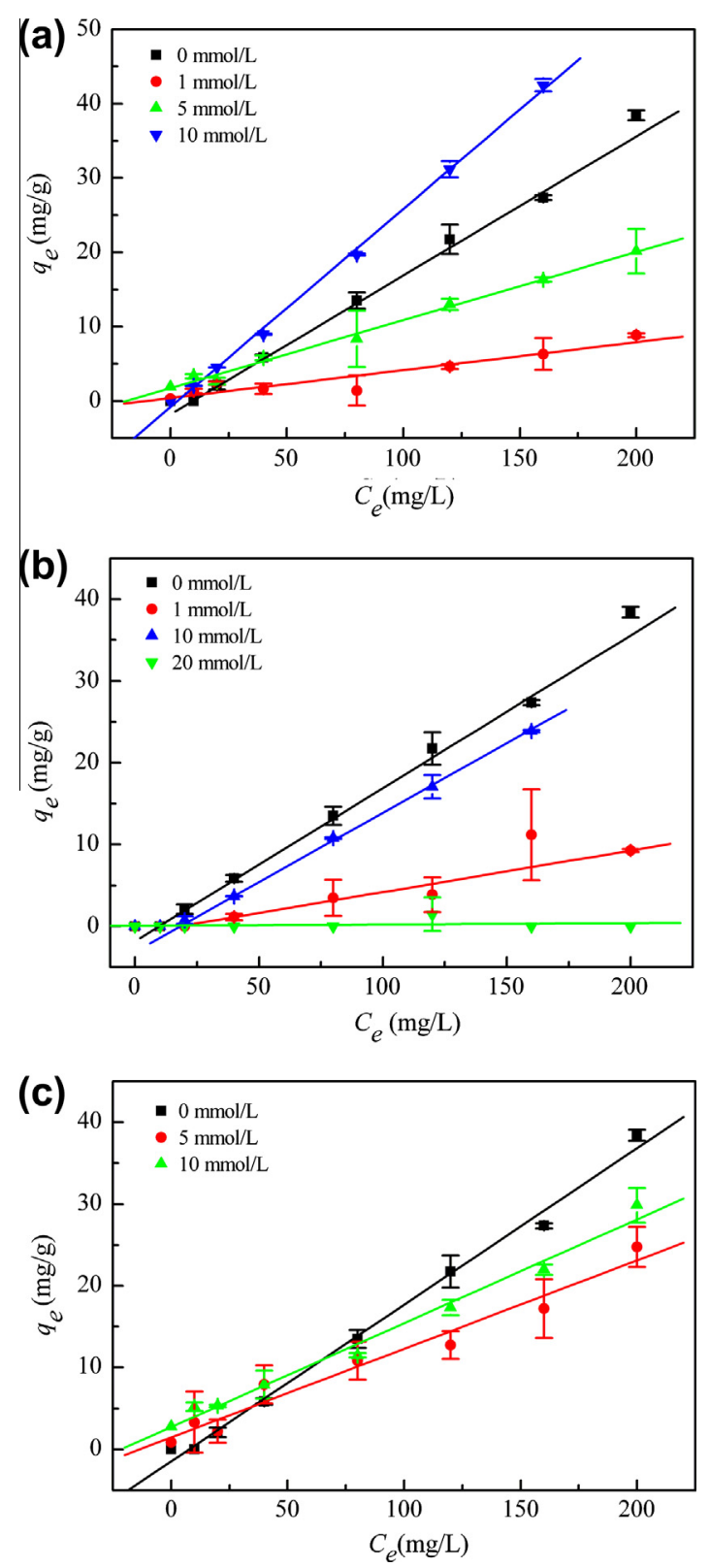

Fig. 3. Adsorption isotherm of 2,4,6-TCP in the presence of surfactant. (a) NaDC, (b) $\mathrm{NaC}$, (c) SDS

the presence of NaDC matched the Henry adsorption isotherm well. When the added NaDC concentration was $1 \mathrm{mmol} / \mathrm{L}$, which was below $\mathrm{CMC}_{1}$, there was a substantial decline in the adsorption capacity. However, as more $\mathrm{NaDC}$ was added to the solution, $5 \mathrm{mmol} / \mathrm{L}$ for example, which was between $\mathrm{CMC}_{1}$ and $\mathrm{CMC}_{2}$ of $\mathrm{NaDC}$, the adsorption capacity began to increase again. Once the added concentration of $\mathrm{NaDC}$ was more than $\mathrm{CMC}_{2}, 10 \mathrm{~mol} / \mathrm{L}$ for example, the adsorption capacity of soil towards 2,4,6-TCP would increase to even higher levels than that in pure water. Thus, in order to remove 2,4,6-TCP to the maximum extent, the concentration of $\mathrm{NaDC}$ should be controlled below $\mathrm{CMC}_{1}$.

Fig. 3b shows the 2,4,6-TCP adsorption isotherm in the presence of $\mathrm{NaC}$ at various concentrations. There was a slight difference in the variation of adsorption capacity compared with NaDC. When the concentration was under $\mathrm{CMC}_{1}$, the adsorption capacity declined quickly. Then, as more $\mathrm{NaC}$ was added (between $\mathrm{CMC}_{1}$ and $\mathrm{CMC}_{2}$ ), the adsorption capacity began to increase again. At this point, the adsorption capacity was close to the initial adsorption in pure water. The most notable phenomenon was that when the added concentration of $\mathrm{NaC}$ exceeded $\mathrm{CMC}_{2}$, the adsorption of 2,4,6-TCP dropped sharply to almost zero. Under these conditions, we can remove the contaminants in the soil completely.

Since the influence of $\mathrm{NaDC}$ or $\mathrm{NaC}$ on solubilization capacities of 2,4,6-TCP is different, it is possible that the influence of $\mathrm{NaDC}$ or $\mathrm{NaC}$ on the adsorption behavior of soil towards 2,4,6-TCP is different. It may be due to the difference in the structure of NaDC and $\mathrm{NaC}$. According to the research of Sobotka, both sides of the molecule are spiked with methyl or hydroxyl groups in $\mathrm{NaC}$, while in NaDC the "lower" side of the molecule has an unbroken frontage of methylene groups. Because the "lower" side of the molecule allows unhindered van der Waals attraction, this specific structure of $\mathrm{NaDC}$ results in the occurance of gel. However, no gelation is observed in the case of $\mathrm{NaC}$ [32].

Fig. 3c shows the adsorption isotherm of 2,4,6-TCP in the presence of SDS at various concentrations. As for SDS, there is only one $\mathrm{CMC}$ and the situation is much simpler. Compared with the adsorption of 2,4,6-TCP in pure water, when the added SDS concentration was below the CMC (e.g. $5 \mathrm{mmol} / \mathrm{L}$ ), the maximum adsorption declined slightly. When the added SDS concentration was above the CMC (e.g. $10 \mathrm{mmol} / \mathrm{L}$ ), the adsorption capacity had a small rebound. However, neither of these concentrations made a huge reduction and the adsorption capacity remained at a high level.

\subsubsection{Solubilization mechanism in the presence of surfactants}

The adsorption process of 2,4,6-TCP in surfactant micelles can be seen as an allocation process [7], and the adsorption mechanism of 2,4,6-TCP in the presence of $\mathrm{NaDC}$ and $\mathrm{NaC}$ described above can be explained by Fig. 4 . When no NaDC was added to the solution, there was a good deal of 2,4,6-TCP adsorbed onto the soil surface (Fig. 4a). When $1 \mathrm{mmol} / \mathrm{L} \mathrm{NaDC}$ was added to the solution, since the added concentration was below $\mathrm{CMC}_{1}$, NaDC in the solution existed in monomeric form. 2,4,6-TCP began to redistribute between the soil surface and the NaDC monomers. The result was that 2,4,6TCP was more inclined to be allocated in the solution, as shown in Fig. $4 \mathrm{~b}$. Therefore, the adsorption capacity of soil towards 2,4,6-TCP declined. As more NaDC was added to the solution, $5 \mathrm{mmol} / \mathrm{L}$ for example, between $\mathrm{CMC}_{1}$ and $\mathrm{CMC}_{2}$, NaDC began to form primary aggregates, as shown in Fig. 4c. These small aggregates would cover the hydrophobic 2,4,6-TCP which would be inside the aggregate and therefore dissolved in the solution, further increasing the quantity of dissolved 2,4,6-TCP. However, as the primary aggregates adsorbed on the soil matrix, it would lead to 2,4,6-TCP partitioning into immobile adsorbed surfactants [17], so that the adsorption capacity had a small rebound. Once the added concentration of $\mathrm{NaDC}$ exceeded $\mathrm{CMC}_{2}$, the quantity of 2,4,6-TCP adsorbed onto the soil surface would increase substantially, as shown in Fig. 4d. This was because secondary aggregates began to form in the solution, and as the secondary aggregates adsorbed onto the soil matrix, the adsorption capacity increased further. This result was consistent with a previous study [39], where they observed that at low concentrations, surfactants are not likely to increase contaminant partitioning into the soil phase. However, the soilwater partition coefficient of the contaminant increased at higher nonionic surfactant doses.

In the case of $\mathrm{NaC}$, the variation of adsorption capacity was similar with $\mathrm{NaDC}$ below $\mathrm{CMC}_{2}$ (Fig. $4 \mathrm{e}-\mathrm{g}$ ). When the added concentration of $\mathrm{NaC}$ was below $\mathrm{CMC}_{1}$, the adsorption capacity decreased as 2,4,6-TCP redistributed into the solution. When the added concentration of $\mathrm{NaC}$ was between $\mathrm{CMC}_{1}$ and $\mathrm{CMC}_{2}$, the adsorption capacity began to increase again and the adsorption capacity reached a relatively high level, as shown in Fig. 4g. In this case, it can be understood as there were two kinds of $\mathrm{NaC}$ micelles. One was the micelle phase dissolved in solution, and the other was 


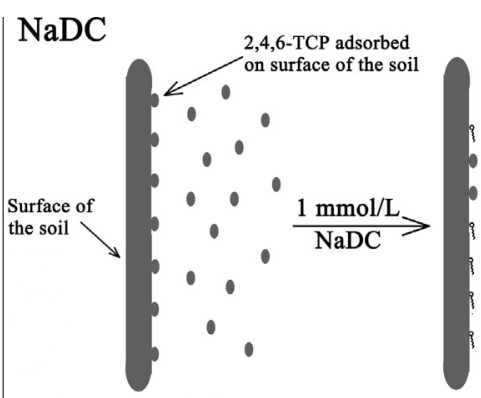

(a)

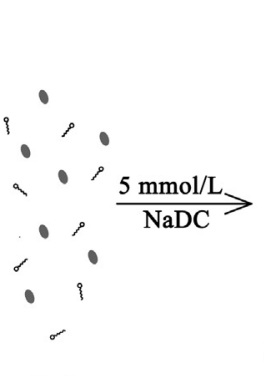

(b)

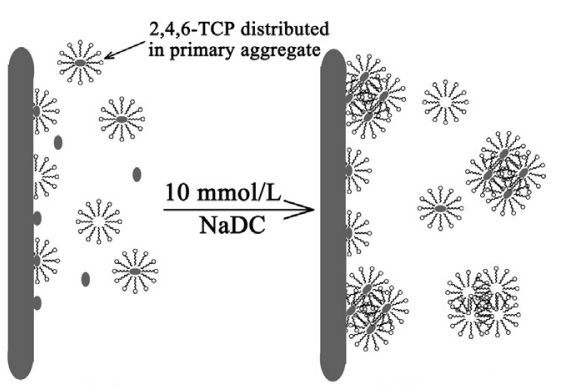

(c) (d)

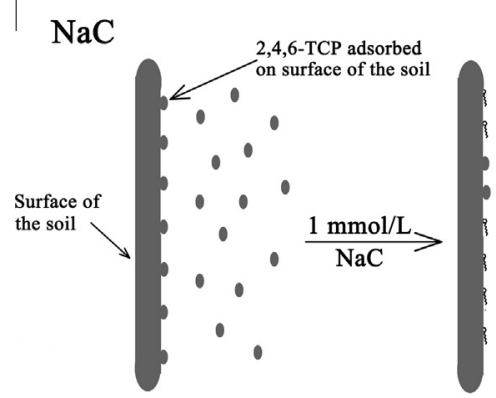

(e)

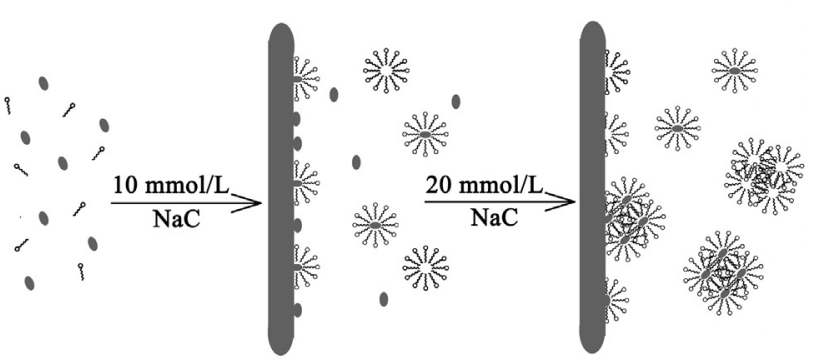

(g) (f) (h)

- 2,4,6-TCP an Monomer afo

Fig. 4. Schematic diagram for the adsorption mechanism of 2,4,6-TCP in the presence of NaDC and $\mathrm{NaC}$.

adsorbed on the soil surface. The latter would result in increased 2,4,6-TCP adsorption onto soil until 2,4,6-TCP solubilization by the micelle phase surfactant successfully competed with increased 2,4,6-TCP sorption onto surfactant-modified soil [2]. HOCs distributed between the mobile and immobile phases varied with surfactant dose due to competition between adsorbed and micelle phase surfactant [20]. In the case of Fig. $4 \mathrm{~g}$, since the concentration of primary aggregates in the solution was relatively low, the 2,4,6-TCP was more inclined to associate with the micelles adsorbed onto the soil surface, which led to a rebound in adsorption capacity. Then, with the increasing of $\mathrm{NaC}$ concentration, the micelle concentration increased. Once the $\mathrm{NaC}$ concentration exceeded $\mathrm{CMC}_{2}$, secondary aggregates began to appear. In the case of Fig. $4 \mathrm{~h}$, the concentration of $\mathrm{NaC}$ micelles was so large that almost all of the 2,4,6-TCP was redistributed into the solution and the quantity of 2,4,6-TCP adsorbed onto the soil surface was almost zero.

The adsorption mechanism of SDS can be explained as follows: When the added concentration of SDS was below CMC, some of the 2,4,6-TCP adsorbed onto the soil surface was desorbed and distributed into the monomers in solution, which led to a decrease in the adsorption capacity. Then, when the added concentration of SDS was above CMC, as more micelles were adsorbed on the soil surface, there was a small rebound in the adsorption capacity.

\section{Conclusions}

NaDC demonstrated the highest solubilization potential, followed by $\mathrm{NaC}$, SDS and $\beta-\mathrm{CD}$. The optimum $\mathrm{pH}$ for $\mathrm{NaDC}, \mathrm{NaC}$, SDS and $\beta$-CD were $7.5,8,7$ and 7 , respectively. The solubility of $2,4,6$-TCP was enhanced a maximum of 72 times by $\mathrm{NaDC}$ at $\mathrm{pH}$ 7.5 .

The adsorption behavior of 2,4,6-TCP was affected by the types of surfactant and its existing forms. The distinctions in adsorption behaviors in the presence of surfactants can be attributed to the redistribution of 2,4,6-TCP between the micellar phase surfactant and the adsorbed surfactant. Compared with traditional surfactants, NaDC and $\mathrm{NaC}$ are more environmental friendly due to the superiority of biodegradability. Both of them can be used as outstanding surfactants for surfactant enhanced soil remediation.

\section{Acknowledgement}

This work is supported by Program for New Century Excellent Talents in University, Ministry of Education, China (NCET-120429).

\section{References}

[1] W. Zhou, J. Yang, L. Lou, L. Zhu, Solubilization properties of polycyclic aromatic hydrocarbons by saponin, a plant-derived biosurfactant, Environmental Pollution 159 (2011) 1198-1204.

[2] S. Laha, B. Tansel, A. Ussawarujikulchai, Surfactant-soil interactions during surfactant-amended remediation of contaminated soils by hydrophobic organic compounds: a review, Journal of Environmental Management 90 (2009) 95-100.

[3] F.I. Khan, T. Husain, R. Hejazi, An overview and analysis of site remediation technologies, Journal of Environmental Management 71 (2004) 95-122.

[4] E. Riser-Roberts, Remediation of Petroleum Contaminated Soils: Biological, Physical, and Chemical Processes, CRC, 1998.

[5] J. Kim, J. Wainaina, J.S. Na, Synthesis of amphiphilic silica/polymer composite nanoparticles as water-dispersible nano-absorbent for hydrophobic pollutants, Journal of Industrial and Engineering Chemistry 17 (2011) 681-690.

[6] J. Wan, L.L. Wang, X. Lu, Y. Lin, S. Zhang, Partitioning of hexachlorobenzene in a kaolin/humic acid/surfactant/water system: combined effect of surfactant and soil organic matter, Journal of Hazardous Materials 30 (2011) 79-85.

[7] D.E. Kile, C.T. Chiou, Water solubility enhancements of DDT and trichlorobenzene by some surfactants below and above the critical micelle concentration, Environmental Science \& Technology 23 (1989) 832-838.

[8] K. Yang, L. Zhu, B. Xing, Enhanced soil washing of phenanthrene by mixed solutions of TX100 and SDBS, Environmental Science \& Technology 40 (2006) 4274-4280.

[9] M. Davezza, D. Fabbri, A.B. Prevot, E. Pramauro, Removal of alkylphenols from polluted sites using surfactant-assisted soil washing and photocatalysis, Environmental Science and Pollution Research 18 (2011) 783-789. 
[10] S. Deshpande, B. Shiau, D. Wade, D. Sabatini, J. Harwell, Surfactant selection for enhancing ex situ soil washing, Water Research 33 (1999) 351-360.

[11] J.F. Lee, M.H. Hsu, H.P. Chao, H.C. Huang, S.P. Wang, The effect of surfactants on the distribution of organic compounds in the soil solid/water system, Journal of Hazardous Materials 114 (2004) 123-130.

[12] P.S. Sales, R.H. de Rossi, M.A. Fernández, Different behaviours in the solubilization of polycyclic aromatic hydrocarbons in water induced by mixed surfactant solutions, Chemosphere 84 (2011) 1700-1707.

[13] M.E. Brewster, T. Loftsson, Cyclodextrins as pharmaceutical solubilizers, Advanced Drug Delivery Reviews 59 (2007) 645-666.

[14] M. Almgren, Mixed micelles and other structures in the solubilization of bilayer lipid membranes by surfactants, Biochimica et Biophysica Acta 1508 (2000) 146-163.

[15] I.F. Paterson, B.Z. Chowdhry, P.J. Carey, S.A. Leharne, Examination of the adsorption of ethylene oxide-propylene oxide triblock copolymers to soil, Journal of Contaminant Hydrology 40 (1999) 37-51.

[16] S. Peng, W. Wu, J.J. Chen, Removal of PAHs with surfactant-enhanced soil washing: influencing factors and removal effectiveness, Chemosphere 82 (2011) 1173-1177.

[17] S. Paria, Surfactant-enhanced remediation of organic contaminated soil and water, Advances in Colloid and Interface Science 138 (2008) 24-58.

[18] S. Paria, P.K. Yuet, Solubilization of naphthalene by pure and mixed surfactants, Industrial \& Engineering Chemistry Research 45 (2006) 35523558.

[19] S. Sun, W.P. Inskeep, S.A. Boyd, Sorption of nonionic organic compounds in soil-water systems containing a micelle-forming surfactant, Environmental Science \& Technology 29 (1995) 903-913.

[20] S.O. Ko, M.A. Schlautman, E.R. Carraway, Effects of solution chemistry on the partitioning of phenanthrene to sorbed surfactants, Environmental Science \& Technology 32 (1998) 3542-3548.

[21] K. Esumi, Y. Sakamoto, T. Nagahama, K. Meguro, Adsolubilization behavior of dyes caused by mixed surfactant bilayers formed on alumina, Bulletin of the Chemical Society of Japan 62 (1989) 2502-2511.

[22] C. Mulligan, R. Yong, B. Gibbs, Surfactant-enhanced remediation of contaminated soil: a review, Engineering Geology 60 (2001) 371-380.

[23] K. Hanna, C. De Brauer, P. Germain, Solubilization of the neutral and charged forms of 2,4,6-trichlorophenol by $\beta$-cyclodextrin, methyl- $\beta$-cyclodextrin and hydroxypropyl- $\beta$-cyclodextrin in water, Journal of Hazardous Materials 100 (2003) 109-116.

[24] K. Matsuoka, Y. Moroi, Micelle formation of sodium deoxycholate and sodium ursodeoxycholate (Part 1), Biochimica et Biophysica Acta (BBA) - Molecular and Cell Biology of Lipids 1580 (2002) 189-199.
[25] S. Lima, C. Andrade-Dias, A.M.A. Dias, I.M. Marrucho, J.A.P. Coutinho, J.J.C. Teixeira-Dias, How does $\beta$-cyclodextrin affect the aggregation of sodium perfluoroheptanoate in aqueous solution: a 19 F NMR study, Journal of Inclusion Phenomena and Macrocyclic Chemistry 57 (2007) 157-162.

[26] B.R. Fillipi, L.W. Brant J.F. Scamehorn, S.D. Christian, Use of micellar-enhanced ultrafiltration at low surfactant concentrations and with anionic-nonionic surfactant mixtures, Journal of Colloid and Interface Science 213 (1999) 68-80.

[27] H.L. Huang, W.M.G. Lee, Enhanced naphthalene solubility in the presence of sodium dodecyl sulfate: effect of critical micelle concentration, Chemosphere 44 (2001) 963-972.

[28] Y. Wen, W.D. Marshall, Simultaneous mobilization of trace elements and polycyclic aromatic hydrocarbon (PAH) compounds from soil with a nonionic surfactant and [S,S]-EDDS in admixture: metals, Journal of Hazardous Materials 197 (2011) 361-368.

[29] H. Guo, Z. Liu, S. Yang, C. Sun, The feasibility of enhanced soil washing of pnitrochlorobenzene ( $\mathrm{pNCB}$ ) with SDBS/Tween80 mixed surfactants, Journal of Hazardous Materials 170 (2009) 1236-1241.

[30] C.T. Jafvert, L.V. Patricia, J.K. Heath, Solubilization of non-polar compounds by non-ionic surfactant micelles, Water Research 28 (1994) 1009-1017.

[31] A.F. Hofmann, K.J. Mysels, Bile salts as biological surfactants, Colloids and Surfaces 30 (1987) 145-173.

[32] H. Sobotka, N. Czeczowiczka, The gelation of bile salt solutions, Journal of Colloid Science 13 (1958) 188-191.

[33] T.B. Boving, M.L. Brusseau, Solubilization and removal of residual trichloroethene from porous media: comparison of several solubilization agents, Journal of Contaminant Hydrology 42 (2000) 51-67.

[34] D.A. Edwards, R.G. Luthy, Z. Liu, Solubilization of polycyclic aromatic hydrocarbons in micellar nonionic surfactant solutions, Environmental Science and Technology 25 (1991) 127-133.

[35] F. Kuni, A. Shchekin, A. Rusanov, A. Grinin, Concentrations of monomers and cylindrical micelles above the second CMC, Colloid Journal 66 (2004) 174-185.

[36] N.A. Mazer, M.C. Carey, R.F. Kwasnick, G.B. Benedek, Quasielastic light scattering studies of aqueous biliary lipid systems. Size, shape, and thermodynamics of bile salt micelles, Biochemistry 18 (1979) 3064-3075.

[37] S. May, A. Ben-Shaul, Molecular theory of the sphere-to-rod transition and the second CMC in aqueous micellar solutions, The Journal of Physical Chemistry B 105 (2001) 630-640.

[38] N.T. Program, Report on Carcinogens, DIANE Publishing, US, 2011.

[39] C. Beigel, E. Barriuso, R. Calvet, Sorption of low levels of nonionic and anionic surfactants on soil: effects on sorption of triticonazole fungicide, Pest Management Science 54 (1998) 52-60. 